\title{
Study on Catastrophic Air Current Early-warning and Control System of Coalmines
}

\author{
L.F. Fang ${ }^{1,2^{*}}$, X.D. Li ${ }^{1,2}$, G.D. Yu ${ }^{3}$, and Y.J. Yao ${ }^{4}$ \\ ${ }^{1}$ Key Laboratory of Ministry of Education for Mine Disaster Prevention and Control, Shandong University of Science and Technology, \\ Qingdao 266590, China \\ ${ }^{2}$ Shandong University of Science and Technology, College of Mining and Safety Engineering, Qingdao 266590, China \\ ${ }^{3}$ Department of industrial \& systems engineering, National University of Singapore, 119077, Singapore \\ ${ }^{4}$ China National Heavy Duty Truck Group Co., Ltd, Jinan 250017, China
}

Received 20 November 2016; Accepted 10 February 2016

\begin{abstract}
Catastrophic air current significantly influences the stability of ventilation system, and existing studies have not considered the flow characteristics of catastrophic air current when designing the control systems. To analyze the effects of different kinds of coalmine accidents on safety production, grey relation entropy theory was used to analyze the hazard assessment of coalmine accidents. Fluent software was employed to study the flow characteristics of catastrophic air current, and the catastrophic air current early-warning and control system of coalmine was researched according to the theoretical analysis and numerical simulation. The threat of fire accidents and roof accidents were larger than other accidents. The influence of temperature and $\mathrm{CO}$ volume fraction distribution of fire accidents to the tailwind side was larger than that of the weather side, and gradient decreased on the weather side. This system can effectively control the spread of fire and poisonous gas, and can judge the accident location immediately. The research effectively guaranteed the safety of mine production.
\end{abstract}

Keywords: Grey Relation Entropy Theory, Numerical Simulation, Catastrophic Air Current, Early-warning and Control

\section{Introduction}

Mine ventilation is one of the main technical means for ensuring safety production. Fresh air is transported from the ground to different downhole locations during the production process, which provides breathing for workers and can dilute and eliminate all kinds of poisonous and harmful gases and mine dust. The establishment of a scientific and reasonable ventilation system is a basic guarantee for mine safety production, and is an economic way to improve the safe production level of a coalmine [1], [2], [3].

As the mining level extends continuously, the stability of ventilation system is increasingly important for mine safety. Gas explosion, fire, and other disasters or accidents have a significant influence on the ventilation system [4]. The threat of these disasters or accidents increases as the mining level extends. These disasters or accidents can easily induce serious secondary disasters such as air escape branches and poisoning, which can increase loss and harm. Accidents not only affect the economic benefits of the mine, but also seriously threaten workers' lives, safety, and social stability. How to warn and control these disasters or accidents has been the primary issue to solve in mining works. The main methods of related research on ventilation system are theoretical analysis and numerical simulation.

\footnotetext{
*E-mail address: zijhflf@163.com ISSN: 1791-2377 @ 2016 Eastern Macedonia and Thrace Institute of Technology. All rights reserved.
}

\section{State of the art}

Domestic and foreign scholars conducted many studies on the stability of ventilation systems for mine disasters. The main research direction includes the following aspects: the stability of ventilation system of coalmines and its evaluation, numerical simulation of ventilation systems, and air current control system. Existing research analysis did not classify the mine disaster and accident, and only used simple methods as air-doors to control the ventilation system.

(1) Stability of the ventilation system of coalmines and its evaluation

The fuzzy mathematics method was applied to the comprehensive judgment on factors of the mine ventilation system based on the study on related stability [5]. The characteristics of heat pressure and thermal resistance of airflow produced by different heat sources were studied and the discriminant of airflow direction affected by heat pressure was obtained [6]. A force auxiliary ventilation system was adopted as a control method in successful extraction and recovery, and booster fans and ventilation control devices such as doors and regulators were used in the system [7]. The results of experimental investigations on catalytic oxidation of coalmine ventilation air methane in a preheated catalytic reaction reactor were presented [8]. The discriminant of the stability of the airflow at mining areas was educed in this study, idiographic prevent measures were proposed, and the conclusion was important to the safety of coal mining production [9].

(2) Numerical simulation of ventilation system 
A numerical simulation for airflow and gas distribution regulation in the goaf of the mechanized working face were obtained using Fluent software [10]. Finite element computer numerical simulation and visual display were used to thoroughly study the airflow pattern and its calculation in the goaf [11]. Measurements using tracer gas technique and evaluation of effective axial diffusion coefficient were discussed in Cibaliung Underground Mine, Indonesia using numerical simulation [12]. A mathematical model for the calculation of temperature distribution during a fire in a mine was proposed, and depth first search algorithm in artificial intelligence theory was also used to write a program for simulating the spreading process of smoke plume and temperature distribution during a fire [13].

(3) Air current control system

Two kinds of airflow remote control systems were researched. One system used compressed air as a power source, transmitting control signals through a monitor system for the mine environment. The other system used electric power and transmitted control signals through an underground telephone network [14]. A proposal for the control of airflow in a mine fire was proposed through the optimization of air quantity in a ventilation network [15]. Based on mastering airflow stability during a fire, the fire early warning and control system of belt roadway was established and applied to Kongzhuang Coalmine, which was helpful to disaster control and avoidance during belt roadway fires [16].

An applied remote -controlled auto anti-fire door and auto water spraying system were developed, and a ventilation plan and a fire put off method at a fire initial stage were provided for practice [17]. The "10.20" coal and gas outburst accident in Daping coalmine in 2004 was simulated using a self-developed TF1M 3D coalmine ventilation simulation system based on source-containing ventilation theory and numerical simulation technology. The results indicated that the remote -controlled automatic throttle should be actively promoted, which could be controlled in the disaster period and minimize loss [18].

The remainder of this paper was organized as follows. Section 2 used the grey relation entropy theory to analyze the hazard assessment of coalmine accidents to effectively decrease the influence of catastrophic air current to the ventilation system. Section 3 studied the numerical simulation of a specific coalmine using Fluent software. Section 4 designed the early-warning and control system. This system was applied to improve the stability and safety of mine ventilation systems. Conclusions were summarized in Section 5.

\section{Methodology}

\subsection{Analysis of grey relation entropy}

Analysis of grey relation entropy is developed based on grey relational analysis method [19]. [20], [21]. This method uses "entropy" to quantitatively analyze the correlation degree of reference factors and comparative factors. The grey relation entropy method can fully utilize character information[22], [23], [24], [25].

\section{(1) Grey entropy}

Grey entropy is the measurement of a discrete sequence of balance degrees. A larger grey entropy corresponds to a more balanced sequence.
A sequence with incomplete information is the grey connotative sequence. We defined the grey connotative sequence as $X=\left(x_{1}, x_{2}, \cdots, x_{n}\right), x_{j} \geq 0$ and $\sum x_{j}=1$. The grey entropy of $X$ was:

$$
H=-\sum_{j=1}^{n}\left[x_{j} \cdot \ln x_{j}\right]
$$

According to entropy increase theorem, any change that can make the attribute value tends to be uniform average will increase the value of entropy. The grey entropy researched to the maximum value when the attribute value of all sequences was equal.

$$
H_{\max }=\ln n
$$

\section{(2) Distributed mapping}

The sum of the value of all elements within the same sequence was set to 1 to obtain the grey relational coefficient before meeting the requirements of the gray entropy. The distributed mapping grey incidence coefficients were as follows:

$$
\begin{aligned}
& R_{i} \rightarrow P_{i} \\
& P_{i}(k)=\frac{\gamma\left[x_{0}(k), x_{i}(k)\right]}{\sum_{k=1}^{n} \gamma\left[x_{0}(k), x_{i}(k)\right]}
\end{aligned}
$$

The mapping value represented the degree of correlation of reference factors $X_{0}$ and comparative factors $X_{i}$ at $k$ point. $P_{i}(k)$ satisfied the formula as follows:

$$
P_{i}(k) \geq 0 \text { and } \sum_{k=1}^{n} P_{i}(k)=1
$$

\section{(3) Grey relation entropy}

The grey relation entropy of comparative factors $X_{i}$ was:

$$
H_{i}=-\sum_{k=1}^{n}\left[P_{i}(k) \cdot \ln P_{i}(k)\right]
$$

where $P_{i}(k) \geq 0$ and $\sum_{k=1}^{n} P_{i}(k)=1$.

The grey incidence coefficient was a kind of grey entropy because the distribution mapping was conducted on the grey incidence coefficient. Entropy increase theorem was appropriate for the grey relation entropy. The degree of correlation of reference factors $X_{0}$ and comparative factors $X_{i}$ increased as the grey relation entropy $H_{i}$ increased.

(4) Correlation degree of grey entropy

We set the factor sets of grey relation as $X$, $X_{i}(k) \in X, \quad i=1,2, \cdots, m, k=1,2, \cdots, n . H_{i}$ was the grey relation entropy of comparative sequence $X_{i}$. The 
correlation degree of grey entropy of comparative sequence $X_{i}$ was:

$$
E_{i}=\frac{H_{i}}{H_{\max }}
$$

\subsection{Establishment of Model in Fluent}

Fluent software is suitable for the numerical simulation of fluid. Therefore, this method was chosen to research the ventilation system of coalmines. To study the flow characteristics of catastrophic air current, the 9th mining area of Nantun Coalmine was selected as the object of study. The -350 connection roadway of 9 th mining area was simplified to meet the requirements of numerical simulation by Fluent.

The length of the roadway was shortened and the width remained unchanged. The section and height were $3 \mathrm{~m}$ and $2.6 \mathrm{~m}$. The fire source was set $5 \mathrm{~m}$ before the inlet with a volume of $3 \times 1 \times 1 \mathrm{~m}$. Before the automatic air-door worked, the catastrophic air current entered the working face along the track down entry of the 9th mining area. After the automatic air-door worked, the catastrophic air current interdicted and entered the return air down entry of the 9th mining area through the automatic air-door. The mesh model of the -350 connection roadway of 9th mining area is shown in Figure 1.


Automatic air-door open

Fig. 1. Mesh model of the -350 connection roadway of the 9 th mining area

We imported the grid model into Fluent software and exerted the boundary condition. Inlets 1,2 , and 3 were the velocity inlets and the imported material was air. The boundary condition of outflow was free flow. The imported material of inlet fire was a mixture of $\mathrm{CO}_{2}, \mathrm{CO}, \mathrm{C}_{4} \mathrm{H}_{8}$, and $\mathrm{SO}_{2}$.

\section{Result Analysis and Discussion}

4.1 Analysis of hazard assessment of coalmine accidents based on grey relation entropy theory

The death toll and death rate (number of people per million ton) in China from 2004-2014 are shown in Figure 2.

The two groups of data had the same decreasing trend. The data before 2006 was too high and could not represent the production level of coalmines in recent years. Coal production was seriously affected after 2010 with the slowdown in economic growth and the deterioration of the situation of coal economy. Therefore, data from 2006-2010 was chosen for analysis. The kinds of coalmine disasters and accidents were divided into roof accident, fire accident, gas accident, electromechanical accident, explosive accident, transportation accident, flood accident, and other accident. The death toll of each kind of accident in each year was defined as $y_{1}, y_{2}, y_{3}, y_{4}, y_{5}, y_{6}, y_{7}, y_{8}$, as shown in Table 1. The death toll of each kind of accident was defined as the comparative sequence $x_{i}(i=1,2, \cdots 8)$, as shown in Table 2.

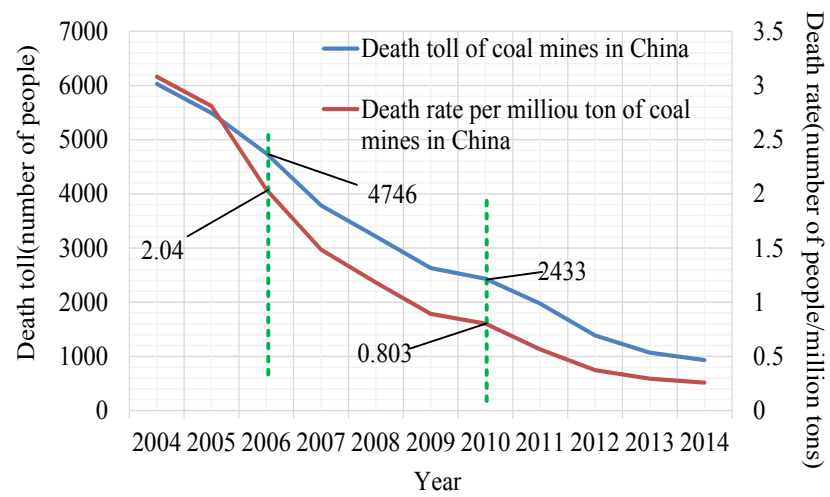

Fig. 2. Death toll and death rate (number of people per million ton) in China from 2004-2014

Table 1. Death toll of each kind of coalmine accident

\begin{tabular}{c|c|c|c|c|c}
\hline \multirow{2}{*}{$\begin{array}{c}\text { Accident } \\
\text { type }\end{array}$} & \multicolumn{5}{|c}{ Death toll(number of people) } \\
\cline { 2 - 6 } & $\mathbf{2 0 0 6}$ & $\mathbf{2 0 0 7}$ & $\mathbf{2 0 0 8}$ & $\mathbf{2 0 0 9}$ & $\mathbf{2 0 1 0}$ \\
\hline$y_{1}$ & 1902 & 1518 & 1222 & 939 & 829 \\
$y_{2}$ & 1319 & 1084 & 778 & 755 & 623 \\
$y_{3}$ & 94 & 86 & 109 & 97 & 78 \\
$y_{4}$ & 517 & 453 & 400 & 319 & 281 \\
$y_{5}$ & 90 & 77 & 55 & 75 & 37 \\
$y_{6}$ & 417 & 255 & 263 & 166 & 224 \\
$y_{7}$ & 26 & 72 & 111 & 31 & 168 \\
$y_{8}$ & 381 & 241 & 277 & 249 & 193 \\
$y_{0}$ & 4746 & 3786 & 3215 & 2631 & 2433 \\
\hline
\end{tabular}

(1) Equalization of original data

To eliminate the influence on grey relation entropy because of the difference of dimension and the absolute value of data, the original data in Table 1 was equalized as was shown in Table 2. 
Table 2. Dimensionless results

\begin{tabular}{c|c|c|c|c|c}
\hline \multirow{2}{*}{$\begin{array}{c}\text { Dimensionless } \\
\text { sequence }\end{array}$} & \multicolumn{5}{|c}{ Dimensionless result } \\
\cline { 2 - 6 } & 2006 & 2007 & 2008 & 2009 & 2010 \\
\hline$X_{0}$ & 1.41 & 1.13 & 0.96 & 0.78 & 0.72 \\
$X_{1}$ & 1.48 & 1.18 & 0.95 & 0.73 & 0.65 \\
$X_{2}$ & 1.45 & 1.19 & 0.85 & 0.83 & 0.68 \\
$X_{3}$ & 1.01 & 0.93 & 1.17 & 1.05 & 0.84 \\
$X_{4}$ & 1.31 & 1.15 & 1.02 & 0.81 & 0.71 \\
$X_{5}$ & 1.35 & 1.15 & 0.82 & 1.12 & 0.55 \\
$X_{6}$ & 1.57 & 0.96 & 0.99 & 0.63 & 0.85 \\
$X_{7}$ & 0.32 & 0.88 & 1.36 & 0.38 & 2.06 \\
$X_{8}$ & 1.42 & 0.90 & 1.03 & 0.93 & 0.72 \\
\hline
\end{tabular}

(2) Grey incidence coefficient $\gamma\left(x_{0}(k), x_{i}(k)\right)$

The grey incidence coefficient in Table 3 was calculated from Table 2 .

Table. 3. Grey incidence coefficient

\begin{tabular}{c|c|c|c|c|c}
\hline \multirow{2}{*}{$\begin{array}{c}\text { Grey incidence } \\
\text { coefficient }\end{array}$} & \multicolumn{4}{|c}{ Grey incidence coefficient value } \\
\cline { 2 - 6 } & $\mathbf{2 0 0 6}$ & $\mathbf{2 0 0 7}$ & $\mathbf{2 0 0 8}$ & $\mathbf{2 0 0 9}$ & $\mathbf{2 0 1 0}$ \\
\hline$\gamma\left(x_{0}(k), x_{1}(k)\right)$ & 0.90 & 0.81 & 1 & 0.91 & 0.90 \\
$\gamma\left(x_{0}(k), x_{2}(k)\right)$ & 0.96 & 0.79 & 0.67 & 0.93 & 0.95 \\
$\gamma\left(x_{0}(k), x_{3}(k)\right)$ & 0.59 & 0.45 & 0.49 & 0.49 & 0.86 \\
$\gamma\left(x_{0}(k), x_{4}(k)\right)$ & 0.86 & 1 & 0.79 & 1 & 0.99 \\
$\gamma\left(x_{0}(k), x_{5}(k)\right)$ & 0.91 & 0.98 & 0.61 & 0.42 & 0.80 \\
$\gamma\left(x_{0}(k), x_{6}(k)\right)$ & 0.78 & 0.51 & 0.86 & 0.64 & 0.85 \\
$\gamma\left(x_{0}(k), x_{7}(k)\right)$ & 0.34 & 0.40 & 0.34 & 0.38 & 0.34 \\
$\gamma\left(x_{0}(k), x_{8}(k)\right)$ & 1 & 0.42 & 0.74 & 0.66 & 1 \\
\hline
\end{tabular}

(3) Grey incidence density value $P_{i}(k)$

The grey incidence density value $P_{i}(k)$ was calculated using reference sequence $X_{0}$ and comparative sequence $X_{i}$ as Formula (3.3), as shown in Table 4.

Table. 4. Grey incidence density value

\begin{tabular}{c|c|c|c|c|c}
\hline \multirow{2}{*}{$\begin{array}{c}\text { Grey incidence } \\
\text { density }\end{array}$} & \multicolumn{5}{|c}{ Grey incidence density value } \\
\cline { 2 - 6 } & $\mathbf{2 0 0 6}$ & $\mathbf{2 0 0 7}$ & $\mathbf{2 0 0 8}$ & $\mathbf{2 0 0 9}$ & $\mathbf{2 0 1 0}$ \\
\hline$P_{1}(k)$ & 0.20 & 0.18 & 0.22 & 0.20 & 0.20 \\
$P_{2}(k)$ & 0.22 & 0.18 & 0.16 & 0.22 & 0.22
\end{tabular}

\begin{tabular}{l|c|c|c|c|c}
$P_{3}(k)$ & 0.20 & 0.16 & 0.17 & 0.17 & 0.30 \\
$P_{4}(k)$ & 0.19 & 0.22 & 0.17 & 0.22 & 0.21 \\
$P_{5}(k)$ & 0.24 & 0.26 & 0.16 & 0.11 & 0.22 \\
$P_{6}(k)$ & 0.22 & 0.14 & 0.24 & 0.18 & 0.23 \\
$P_{7}(k)$ & 0.19 & 0.22 & 0.19 & 0.21 & 0.19 \\
$P_{8}(k)$ & 0.26 & 0.11 & 0.19 & 0.17 & 0.26 \\
\hline
\end{tabular}

(4) Grey relation entropy

Grey relation entropy $H_{i}$ was calculated using comparative sequence $X_{i}$ as Formula (3.4), as shown in Table 5.

Table 5. Grey relation entropy

\begin{tabular}{c|c|c|c|c|c|c|c|c}
\hline $\begin{array}{c}\text { Grey } \\
\text { relation } \\
\text { entropy }\end{array}$ & $H_{1}$ & $H_{2}$ & $H_{3}$ & $H_{4}$ & $H_{5}$ & $H_{6}$ & $H_{7}$ & $H_{8}$ \\
\hline Value & 1.61 & 1.60 & 1.58 & 1.60 & 1.57 & 1.59 & 1.61 & 1.57 \\
\hline
\end{tabular}

(5) Grey correlation degree

The grey correlation degree $E_{i}$ were calculated as Formula (3.5): $E_{1}=0.772898, \quad E_{2}=0.769809$, $E_{3}=0.759441, E_{4}=0.771735, E_{5}=0.754789$, $E_{6}=0.765311, E_{7}=0.772755, E_{8}=0.752606$.

The degree of influence is: $y_{1}>y_{7}>y_{4}>y_{2}>y_{6}$ $>y_{3}>y_{5}>y_{8}$ (roof accident $>$ fire accident $>$ transportation accident $>$ gas accident $>$ flood accident $>$ electromechanical accident $>$ explosive accident $>$ other accident).

(6) Result analysis

The result of grey relation entropy analysis shows that roof, fire, transportation, and gas accidents were more harmful than the other types of accidents were.

According to relevant data, in all accident types, the frequency of roof accident was the highest, accounting for $54.42 \%$ of total accidents. The perniciousness of fire accident was the most, with 9.25 deaths per accident. The frequency and death toll of gas accidents were $17.10 \%$ and $34.41 \%$. Of all coalmines in China, $56 \%$ are mining the spontaneous combustion coal seam. Fires can provide a combustion source for coal dust and gas explosions, and can release $\mathrm{H}_{2}$, hydrocarbon, and other explosive gases. Fire accidents can easily induce coal dust explosions, gas explosions, and other secondary disasters. Exogenous fire accidents also increase with the increase of the degree of coalmine production mechanization.

Therefore, this study researched the flow regularity of catastrophic air current after fire accidents in coalmines, and worked out the technology and control system to improve ventilation system stability. 
4.2 Numerical simulation analysis of coalmine catastrophic air current after fire accident

\subsubsection{Numerical simulation with the automatic air-door} closed

1) Temperature distribution law

The temperature distribution figures at $\mathrm{t}=10 \mathrm{~s}$ of $\mathrm{X}$ direction $(\mathrm{X}=1 \mathrm{~m}), \quad \mathrm{Y}$ direction $(\mathrm{Y}=1.5 \mathrm{~m})$, and $\mathrm{Z}$ direction $(Z=2.5 \mathrm{~m}, 5 \mathrm{~m}, 10 \mathrm{~m}, 15 \mathrm{~m}, 20 \mathrm{~m}, 25 \mathrm{~m}, 30 \mathrm{~m}$, $35 \mathrm{~m}, 40 \mathrm{~m}, 45 \mathrm{~m}, 50 \mathrm{~m}, 55 \mathrm{~m}, 60 \mathrm{~m}, 65 \mathrm{~m}, 70 \mathrm{~m}, 75 \mathrm{~m}$, and $80 \mathrm{~m}$ ) are shown in Figure 3.

The temperature on the top of the fire source was $1000 \mathrm{~K}$, and was higher than that of the middle and bottom of the roadway. The temperature on the top of the roadway in the range of $30 \mathrm{~m}$ was from $560-599 \mathrm{~K}$, and was 480 $520 \mathrm{~K}$ of the middle and bottom of the roadway. The influence of temperature on fire accidents to tailwind side was larger than that of weather side and gradient decreased on the weather side. The temperature was approximately

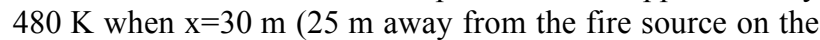
tailwind side). The temperature remained stable at $\mathrm{x}=2.5 \mathrm{~m}$ ( $2.5 \mathrm{~m}$ away from the fire source on the weather side).

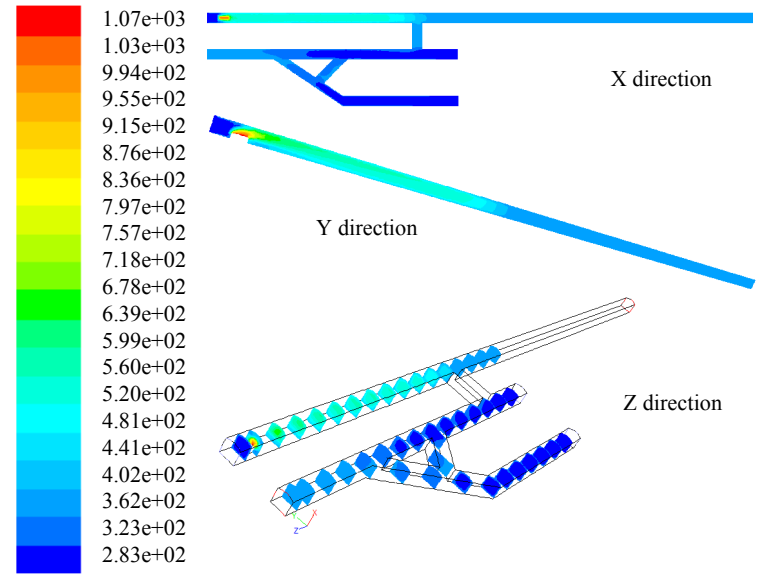

Fig.3. Temperature distribution figure in different directions of the disaster period for the -350 connection roadway of the 9 th mining area

2) CO volume fraction law

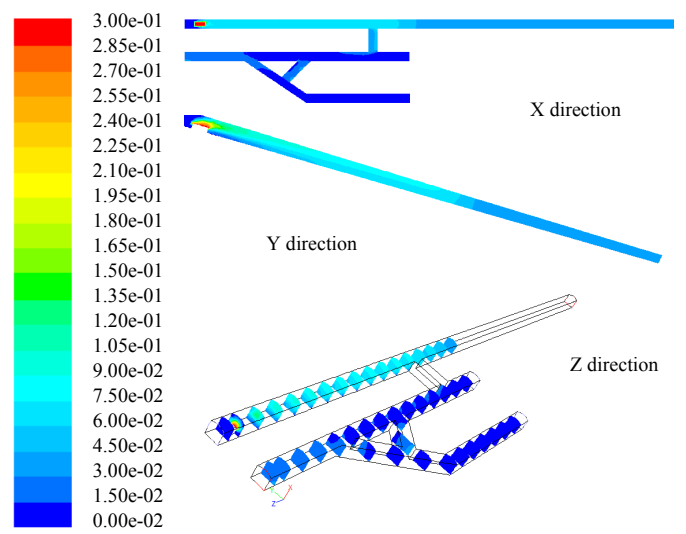

Fig.4. $\mathrm{CO}$ volume fraction figure in different directions of the disaster period for the -350 connection roadway of the 9 th mining area

Figure 4 shows that the $\mathrm{CO}$ spread centered from the fire source after the fire accident occurred, but the diffusion range did not reach the entire roadway. $\mathrm{CO}$ volume fraction reached the maximum at the top of the roadway through buoyancy. The influence of $\mathrm{CO}$ volume fraction on fire accidents to the tailwind side was larger than that of weather side and gradient decreased on the weather side.

\subsubsection{Numerical simulation with the automatic air-door open}

1) Temperature distribution law

The temperature distribution figures at $t=10 \mathrm{~s}$ of $\mathrm{X}$ direction $(X=1 \mathrm{~m}), \quad \mathrm{Y} \quad \operatorname{direction}(\mathrm{Y}=1.5 \mathrm{~m}), \quad \mathrm{Z}$ direction $(Z=2.5 \mathrm{~m}, 5 \mathrm{~m}, 10 \mathrm{~m}, 15 \mathrm{~m}, 20 \mathrm{~m}, 25 \mathrm{~m}, 30 \mathrm{~m}$, $35 \mathrm{~m}, 40 \mathrm{~m}, 45 \mathrm{~m}, 50 \mathrm{~m}, 55 \mathrm{~m}, 60 \mathrm{~m}, 65 \mathrm{~m}, 70 \mathrm{~m}, 75 \mathrm{~m}$, and $80 \mathrm{~m}$ ) are shown in Figure 5.

Contrastive analysis of Figures 3 and 5 showed that the high-temperature region caused by fire would spread along the track down the entry of the 9th mining area. It could then enter the working face of the 9th mining area when the automatic air-door closed. The flow direction of the catastrophic air current would change into the -350 return air down the entry of the 9th mining area when the automatic air-door was open. The high-temperature area had little effect on the working face in the 9th mining area.

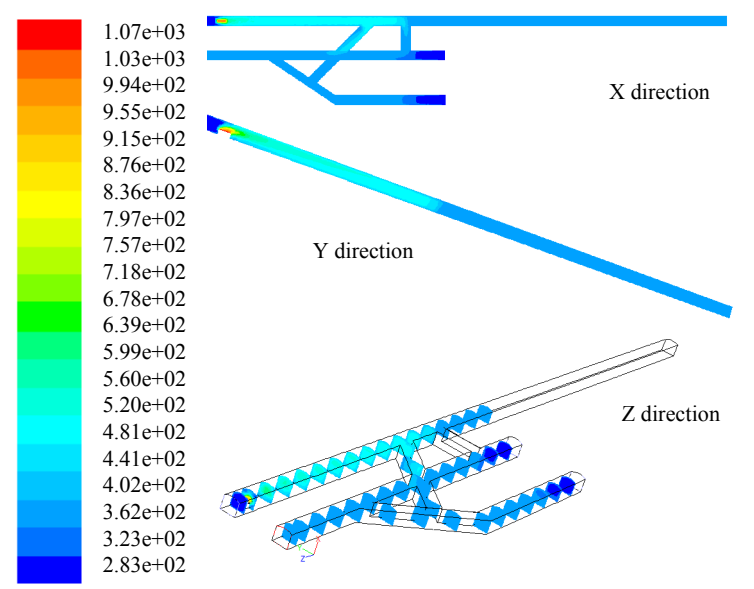

Fig.5. Temperature distribution figure in different directions of the disaster period for the -350 connection roadway of the 9 th mining area

\section{2) $\mathrm{CO}$ volume fraction law}

Contrastive analysis of Figures 4 and 6 showed that $\mathrm{CO}$ would spread along the track down entry of the 9th mining area when the automatic air-door closed. The flow direction of CO would change into the -350 return air down the entry of the 9th mining area. The hazardous gas had little effect on the working face in the 9th mining area.

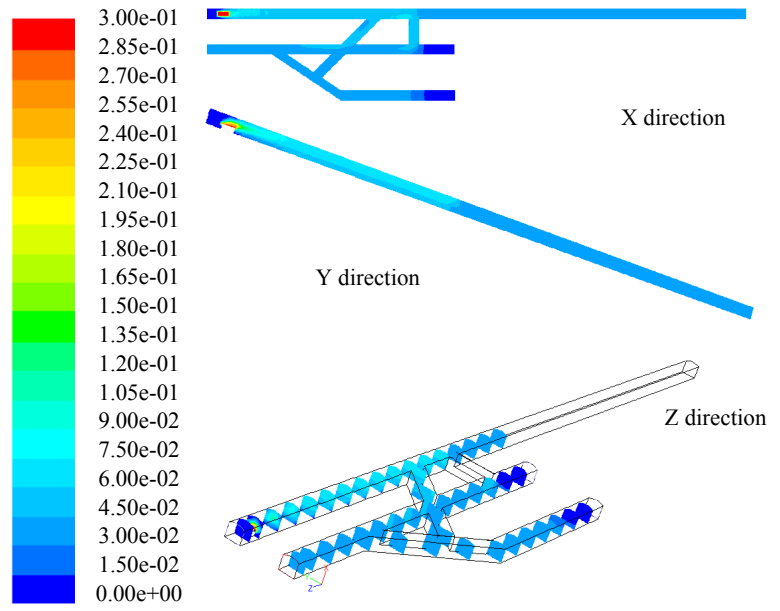

Fig.6. CO volume fraction figure in different directions of the disaster period for the -350 connection roadway of the 9 th mining area 
4.3 Research of Catastrophic air current early-warning and control system

The catastrophic air current early-warning and control system of Nantun Coalmine constituted a remote control system, early-warning system, automatic air-door control system, and alarm system.

\section{1) Remote control system}

The remote control system constituted a monitoring computer, switches, PLC(programmable logic controller), and corresponding control software. The control centers were located in both the ground and underground. During different periods of ventilation, the state of the automatic airdoors, sensors, and alarm devices can be monitored in the control centers. The state of automatic air-doors can be artificially controlled by software in the ground. The automatic air-door can be changed back to the original state.

\section{2) Early-warning system}

This system constituted a smoke transducer, $\mathrm{CO}$ transducer, PLC, telecommunication line, and computer. Transducer data in different locations transferred to the PLC through a public telecommunication line. The PLC sends these data to the control computer through another public telecommunication line through switches. This system achieves centralized information processing and earlywarning, and can send the information to the local area network.

\section{3) Automatic air-door control system}

The automatic air-door control system consisted of automatic air-doors and their accessory devices. The power source of the air-door can be the electrical power system or pressure air power system. The accessory devices mainly included an infrared sensor, photoelectric sensor, automatic controller, and alarm devices.

\section{4) Alarm system}

The alarm devices should be set in all areas that can be affected by catastrophic air currents when fire accidents occur. The alarm devices worked simultaneously with the automatic air-door. The alarm devices were connected to the PLC to realize automatic control, remote control, and condition monitoring.

The catastrophic air current early-warning and control system of Nantun Coalmine includes three groups of automatic air-doors. These air-doors were normally closed during normal production of mine. Six groups of $\mathrm{CO}$ and smoke transducers (G1-G6) are connected to the existing monitoring system for early warning and fire location analysis. The locations of automatic air-doors and transducers are shown in Table 6 and Figures 7-10.

Table 6. Location and control area of automatic air-doors

\begin{tabular}{c|c|c|c}
\hline $\begin{array}{c}\text { Number of } \\
\text { automatic } \\
\text { air-door }\end{array}$ & $\begin{array}{c}\text { Norm } \\
\text { al } \\
\text { state }\end{array}$ & $\begin{array}{c}\text { Emergenc } \\
\text { y state }\end{array}$ & Control area \\
\hline A1 & closed & open & $\begin{array}{c}\text { belt roadways of 9th mining } \\
\text { area }\end{array}$ \\
A2 & closed & open & $\begin{array}{c}\text { NO.3 section of 9th mining } \\
\text { area } \\
\text { AO.1 and NO.2 section of } \\
\text { 9th mining area }\end{array}$ \\
\hline
\end{tabular}

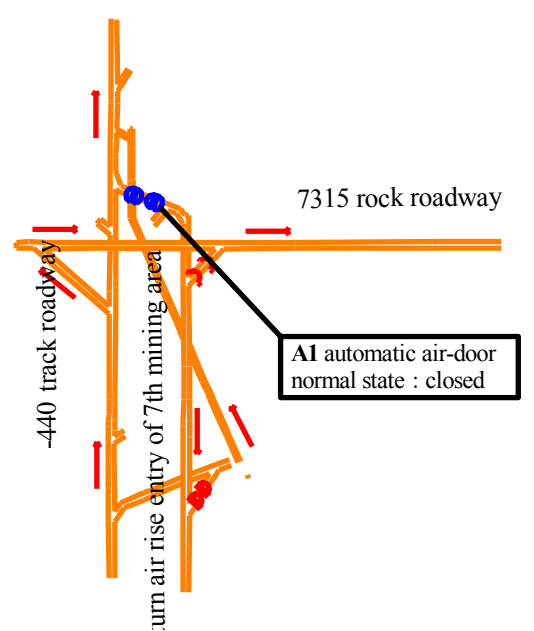

Fig. 7. Diagram of A1 automatic air-door

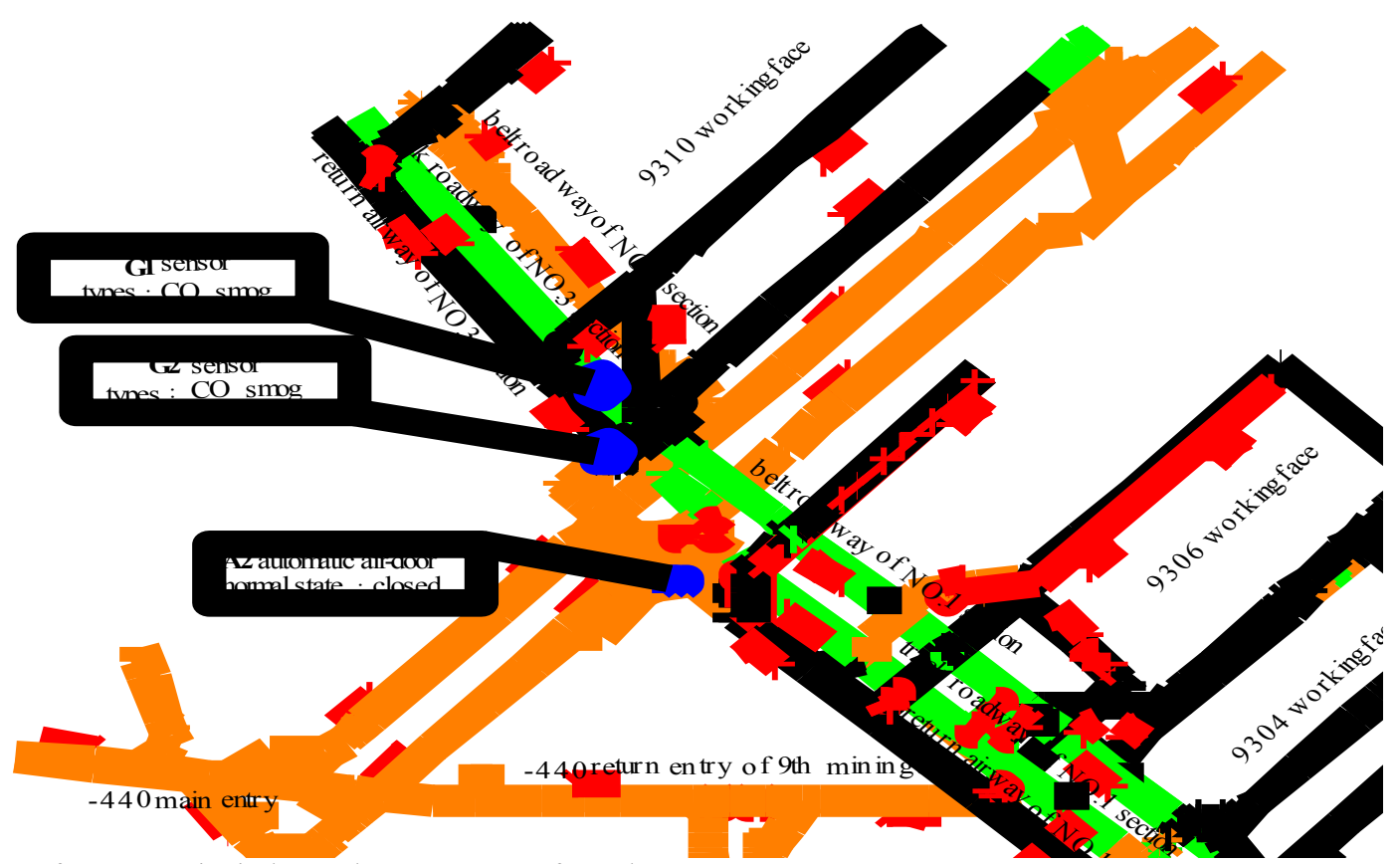

Fig.8. Diagram of A2 automatic air-door and G1, G2 groups of transducer 




Fig.9. G3-G6 groups of transducer

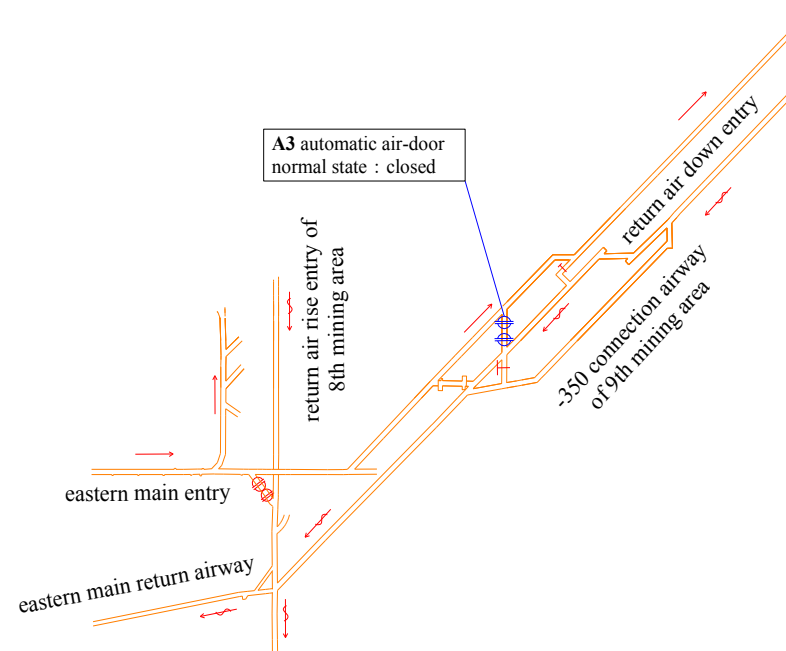

4) Transducers in the working face in the NO.3 section of the 9th mining area and G3 transducer exceeded the critical value

When the transducers in the working face in the NO.3 section of the 9th mining area and G3 transducer exceeded the critical value, the accident location was in the working face in the NO.3 section of the 9th mining area.

5) Transducers in the working face in the NO.1 section of the 9th mining area and G4 transducer exceeded the critical value

When the transducers in the working face in the NO.1 section of the 9th mining area and G4 transducer exceeded the critical value, the accident location was in working face in the NO.1 section of 9th mining area.

6) Transducers in the working face in the NO.2 section of the 9th mining area and G5 transducer exceeded the critical value

When the transducers in the working face in the NO.2

Fig.10. Diagram of A3 automatic air-door

\subsection{Analysis of accident location}

To immediately judge the accident location when the transducers exceeded the critical value and automatic airdoors worked, the possibility of accident location devices was analyzed by the states of the transducers of the catastrophic air current early-warning and control system.

1) G1 transducer exceeds the critical value

When the G1 transducer exceeded the critical value only, the accident location was in the belt roadway of the NO.3 section of the 9th mining area.

2) G3 transducer exceeds the critical value

When the G3 transducer exceeded the critical value only, the accident location was in the belt roadway of the NO.1 section of the 9th mining area.

3) G6 transducer exceeds the critical value

When the G6 transducer exceeded the critical value only, the accident location was in the belt roadway of the NO. 2 section of the 9th mining area. section of the 9th mining area and G5 transducer exceeded the critical value, the accident location was in working face in the NO.2 section of the 9th mining area.

\subsection{Working mechanism of automatic air-door}

In the normal ventilation period, fresh air entered the NO.1 and NO.2 section of the 9th mining area from the eastern main entry, tracked down the entry of the 9th mining area, and reached the working face. The polluted air flowed out through the belt roadway and return airway of each section of the 9th mining area. The fresh air entered the NO.3 section of the 9th mining area from the north main entry of the 7 th mining area and the -440 main entry, and the polluted air flowed out through the belt roadway and return airway of the NO.3 section of the 9th mining area.

The state of the A1 automatic air-door would change to open from closed when the data of the G1 transducer, G3 transducer, or G6 transducer exceeded the critical value. Fresh air from the -440 track roadway turned into the return air rise entry of 7 th mining area. No air current existed in the belt roadway of all sections of the 9th mining area to effectively control the spread of the fire and poisonous gas. 
Workers in the belt roadway of all sections of 9th mining area should evacuate when the alarm system worked.

The state of A2 automatic air-door will change to open from closed when the data of the G2 transducer or transducers in the working face of the NO.3 section of the 9 th mining area exceeded the critical value. Fresh air from the -440 main entry turned into the return airway of the NO.1 section of the 9th mining area. Air current cut off from the -440 main entry turned to the NO.3 section of the 9th mining area.

Two conditions exist wherein the state of A3 automatic air-door will change to open from closed: 1) the data of the G4 transducer and transducers in the working face of the NO.1 section of the 9th mining area exceeded the critical value; 2) the data of the G5 transducer and transducers in the working face of the NO.2 section of the 9th mining area exceeded the critical value. Fresh air from the track down entry of the 9th mining area will enter the eastern main return airway instead of the NO.1 or the NO.2 section of the 9th mining area

Particularly, the control area of the A3 automatic airdoor was the NO.1 and NO.2 section of the 9th mining area. Workers in both sections should evacuate along the evacuation routes when the alarm devices worked.

\section{Conclusions}

To effectively guarantee the safety of mine production, the hazard assessment of coalmine accidents was analyzed based on grey relation entropy theory, and the coalmine catastrophic air current after a fire accident was analyzed using numerical simulation. The following conclusions were made:

1) Roof, fire, transportation, and gas accidents were more harmful than other accidents were. Fire accidents can easily induce coal dust explosions, gas explosions, and other secondary disasters. Research on the catastrophic air current after a fire accident is significant.

2) The temperature distribution and $\mathrm{CO}$ volume fraction law in the conditions of automatic air-doors opening or closing were obtained through numerical simulation. The influence of fire accidents to the tailwind side is larger than that on the weather side.

3) The catastrophic air current early-warning and control system of Nantun Coalmine was designed and implemented. This system included three groups of automatic air-doors and six groups of transducers. The system effectively improved the capability to prevent and mitigate disasters and accidents.

\section{References}

1. Yang S.Q., P W.D., Wen H., Yu B.H., Ma Z.H., Huang R.L., "Theoretical analysis and applications of Y-Inversion Ventilation System in a mine fire zone", Mining Science and Technology, 20(5), 2010, pp. 672-676.

2. Cheng J.W., Yang S.Q., "Data mining applications in evaluating mine ventilation system", Safety Science, 50(4), 2012, pp. 918-922.

3. Jia T.G., Liu J., "Stability of mine ventilation system based on multiple regression analysis", Mining Science and Technology, 19(4), 2009, pp. 463-466.

4. Jia T.G., Wang S.G., Qu G.N., Jia B.S., "Research on the Influence of Airway Sensitivity on the Airflow Stability of Mine Ventilation System”, Journal of Mining \& Safety Engineering, 29(1), 2012, pp. 140-143.

5. Zhu Z.H., Cheng H., Guo L.J., "Judgment on air current stability of mine ventilation system base on fuzzy model", Coal Engineering, 2011, pp. 103-105.

6. Zhang Y.W., Zou S.H., Li Y.C., "Analysis on influence to airflow stability by heat source in high temperature mine", Journal of Safety Science and Technology, 11(8), 2015, pp. 46-51.

7. Wang, G.,Xie J., Xue S., Wang H,y., "Mining a coal seam below a heating goaf with a force auxiliary ventilation system at Longhua underground coal mine, China", International Journal of Mining Science and Technology, 25(1), 2015, pp. 67-72.

8. Zheng B., Liu Y.Q., Liu R.X., Meng J., "Catalytic oxidation of coal mine ventilation air methane in a preheat catalytic reaction reactor", International Journal of Hydrogen Energy, 40(8), 2015, pp. 33813387.

9. Tan Y.Z., Bai N.X., Ma S.L., Zhang J.G., "Effect of Natural Wind Pressure on the Stability of Air Flow at Mining Areas and Its Prevention", Journal of Shandong University of Science and Technology(Natural Science), 24(4), 2005, pp. 7-9+16.

10. Gao J.L., Li X.X., Cui Y.K., "Numerical simulation for airflow and gas distri-bution regulation in the goaf of mechanized working face", Journal of Safety and Environment, 13(2), 2013, pp. 164168.

11. Li Z.X., Hai G.Z., Qin S.Y., "Numerical simulation and visual display of air flow pattern in goaf", Journal of China coal society, 26(1), 2001, pp. 76-80.

12. Widiatmojo A., Sasaki K., Widodo N.P., Sugai Y., Sinaga J., Yusuf H., "Numerical simulation to evaluate gas diffusion of turbulent flow in mine ventilation system", International Journal of Mining Science and Technology, 23(3), 2013, pp. 349-355.
13. Jia J.Z., Ma H., Liu J., "Numerical simulation for temperature distribution during mine fire period", Journal of Liaoning Technical University, 22(4), 2003, pp. 461-464.

14. Wang D.M., Zhang G.W., Bao Q.G., "Study on Remote Control Technology of Airflow during Mine Fire", China Safety Science Journal, 12(1), 2002, pp. 60-63.

15. Li H.H., Huang Y.P., "Optimization of airflow control plan in a mine fire", Journal of china coal society, 21(4), 1996, pp. 407-410.

16. Zhang S.Z., Cheng W.M., Zhang R.M., Liu X.K., "Stability simulation and control technology of airflow during fire in mine belt roadway", Journal of china coal society, 36(5), 2011, pp. 812817.

17. Zhu H.Q., Liu X.S., Zhang W.K., Zhang F.Y., "Research and Application of Auto Air Flow Control System at Initial Mine Fire Accident”, Coal science and technology, 28(2), 2000, pp. 26-28.

18. Li Z.X., Wang Y.D., Gao G.C., "Simulation of 3D mine ventilation system after gas outburst based on source-containing ventilation network", China Safety Science Journal, 25(8), 2015, pp. 43-49.

19. Zhang Q.S., Guo X.J., Deng J.L., "Grey relation entropy method of grey relation analysis", System engineering- theory \& practice, 8 , 1996, pp. 7-11.

20. Zheng X.X., Liu G.P., "Gray Relational Entropy Analysis Based on Coal Mine Accident Type”, Coal technology, 29(8), 2010, pp. 8384.

21. Tseng S.F., Lin J.H., "Evaluating information technology impact on business performance of biotechnology industry using grey relation entropy analysis", Journal of Convergence Information Technology, 7(14), 2012, pp. 297-305.

22. Yang, R.S., Wang X., "Safety evaluation of mine lane tunneling project based on grey relation analysis", 2012 International Conference on Civil, Architectural and Hydraulic Engineering, 2012.

23. Sharma A., Yadava, V., "Optimization of cut quality characteristics during Nd: YAG laser straight cutting of Ni-based superalloy thin sheet using greyrelational analysis with entropy measurement", Materials and Manufacturing Processes, 26(12), pp. 1522-1529.

24. Qiao B., Fang C.L., Ban M.S., "Investigation of the interactive, intimidating relation between urbanization and the environment in an arid area based on grey system theory", Journal of China University of Mining and Technology, 16(4), 2006, pp. 452-456.

25. Lv Q., "The analysis of coal mine safety's grey model in China", International Journal of Advancements in Computing Technology, 4(16), 2012, pp. 470-476. 